\title{
Effect of external conditions and steam parame- ters on performance of combined-cycle power plants with back-pressure steam turbine
}

\author{
Aleksandra Antonova ${ }^{1, *}$, Artem Uvarov ${ }^{1}$ \\ ${ }^{1}$ National Research Tomsk Polytechnic University, 634050 Tomsk, Russia
}

\begin{abstract}
The cogeneration combined-cycle gas turbine plant with backpressure steam turbine is considered. A simple circuit of the plant increases its reliability, and the use of optimal temperatures of the heating and return water allows obtaining the highest thermal efficiency of the plant taking into account the ratio of its electric and heat power. The technical and economic efficiency of the combined-cycle plant with back-pressure steam turbine is studied to estimate the capital investment. The parameters and conditions to maximize the net present value growth relative to the base version are determined.
\end{abstract}

\section{Introduction}

Combined-cycle technologies have occupied a leading position in heat power engineering due to high heat efficiency and environmental friendliness. Generating equipment in domestic thermal power plants and in the world energy is mainly implemented through combined-cycle power plants (CCPP) [1]. In the most efficient binary-cycle CCPP with bottoming cycle and is called a combined cycle gas turbine (CCGT) plant. The exhaust heat of gas turbine (GT) is recovered in a heat recovery steam generator (HRSG) for generation of superheated steam, which then flows to the steam bottoming cycle. The efficiency of these CCGTs based on high-temperature GT reaches $60 \%$ and higher [2,3]. Higher levels of heat efficiency are obtained in cogeneration combined-cycle plants supplied with different cycles and circuits. One of the versions of this plant is CCGT with a back-pressure steam turbine (CCGT-BP) [4].

\section{CCGT with a back-pressure steam turbine}

In CCGT-BP, the exhaust GT gas heat is recovered in HRSG in two sections of the heating cycle: upon supply of the superheated steam (hot water, steam generation, superheating) and during heating the return water in the HRSG back-end surfaces. The heat generated by the exhaust steam is transferred to the steam or to the water supplied directly to the network.

* Corresponding author: anton@tpu.ru 
CCGT-BP is very simple in its design since no several steam pressure levels and reheating are required. Fig. 1 shows a CCGT-BP schematic diagram to supply heat to heat and hot water consumers and for household needs.

The efficiency of HRSG and that of the whole plant can be increased through deep heat recovery due to reduced exhaust gas temperature during transmission of heat to the return heating water in the gas-water network heater $(\mathrm{GWNH})$.

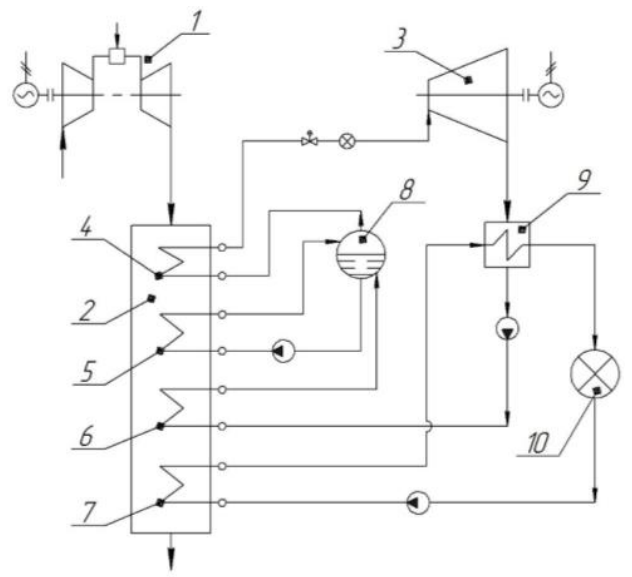

Fig. 1. Schematic diagram of CCGT with a back-pressure steam turbine: GT (1); HRSG (2); steam turbine (3); steam superheater (4); evaporator (5); economizer (6); GWNH (7); drum (8); network heater $(\mathrm{NH})(9)$; heat consumer $(10)$.

The temperature chart of the heat supply system is crucial for the performance of the CCGT-BP steam section, since the temperature of the heating water affects the pressure of the turbine exhaust steam; its value is close to the atmospheric pressure or exceeds it.

\section{Thermal efficiency of CCGT-BP}

The thermal efficiency of CCGT-BP can be estimated using the so-called total efficiency of CCGT, which shows the portion of the fuel heat utilized in the plant.

Utilized heat is the sum of the CCGT electric power $N_{E}$, and heat power transferred to heat consumers $Q_{H C}$. The total efficiency of CCGT

$$
\eta_{C C G T}=\frac{N_{E}+Q_{H C}}{Q_{C C}},
$$

where $Q_{C C}$ is the fuel heat input to the working fluid in the GT combustion chamber.

In turn, the CCGT electric power is the sum of two summands

$$
N_{E}=N_{E}^{G T}+N_{E}^{S T},
$$

where $N_{E}^{G T}$ and $N_{E}^{S T}$ are the electric power of gas and steam turbine.

Transform the formula of the CCGT total efficiency

$$
\eta_{C C G T}=\frac{N_{E}^{G T}}{Q_{C C}}+\frac{N_{E}^{S T}+Q_{H C}}{Q_{C C}}=\eta_{G T}+\frac{Q_{C C} \cdot\left(1-\eta_{G T}\right) \cdot \eta_{H R S G}}{Q_{C C}}=\eta_{G T}+\left(1-\eta_{G T}\right) \cdot \eta_{H R S G}
$$

Thus, the CCGT total efficiency is 


$$
\eta_{C C G T}=\eta_{G T}+\left(1-\eta_{G T}\right) \cdot \eta_{H R S G}
$$

This formula lacks the efficiency of the steam turbine or any other factor that indicates its heat efficiency. Hence, the effectiveness of the combined-cycle plant with a backpressure turbine does not depend on the steam cycle (SC) efficiency. This can be attributed to the fact that SC works without cycle losses: the exhaust steam condensation heat is fully utilized to cover the consumers' heat demands.

In addition to the total efficiency, the most important characteristic of the CCGT-BP heat efficiency is the power ratio $N_{E}{ }^{S T} / Q_{H C}$.

The aim is to study the effect of a number of factors on CCGT-BP heat efficiency. These factors are as follows:

- temperature of the heating water $t_{h w}$,

- temperature of the return water $t_{r w}$,

- initial steam pressure $p_{0}$,

- initial steam temperature $t_{0}$.

In accordance with the recommendations [5], a number of variables are taken:

- evaporator temperature difference $5{ }^{\circ} \mathrm{C}$,

- subcooling to the saturation temperature of $5^{\circ} \mathrm{C}$ in network heater,

- GWNH temperature difference of $5{ }^{\circ} \mathrm{C}$,

- initial steam temperature $t_{0}$.

The design conditions for CCGT-BP imply its operation at external temperature of -40 ${ }^{\circ} \mathrm{C}$ (temperature specified for the heating system design in Tomsk). The key GT characteristics are calculated with regard to its energy parameters; air heating to $3.4{ }^{\circ} \mathrm{C}$ through air recirculation at the compressor outlet is considered. The Siemens SGT5-4000F gas turbine was used as the CCGT-BP basis. The GT performance parameters at external temperature of $-40{ }^{\circ} \mathrm{C}$ are as follows:

- GT load is $100 \%$,

- electrical efficiency is $35.37 \%$,

- electric power is $247.6 \mathrm{MW}$,

- exhaust gas temperature is $594.8^{\circ} \mathrm{C}$,

- exhaust gas flow is $644.9 \mathrm{~kg} / \mathrm{s}$.

The values of the performance parameters for the steam section for the base case are summarized in Table 1 .

Table 1. Main parameters of the steam section of CCGT-BP and its efficiency for the base case.

\begin{tabular}{|c|c|c|}
\hline No & Parameter, dimension & Value \\
\hline 1 & Initial steam pressure, MPa & 5.0 \\
\hline 2 & Initial steam temperature, ${ }^{\circ} \mathrm{C}$ & 540 \\
\hline 3 & Electric power, MW & 68.51 \\
\hline 4 & Heat power, MW & 302.9 \\
\hline 5 & Heating water temperature, ${ }^{\circ} \mathrm{C}$ & 110 \\
\hline 6 & HRSG efficiency & 0.828 \\
\hline 7 & CCGT total efficiency & 0.885 \\
\hline 8 & Total capital investments, mln. USD & 156.3 \\
\hline 9 & Net present value (NPV), mln. USD & 547.9 \\
\hline
\end{tabular}

The model was made in "MathCad" software and tested in the special "Thermoflex" complex.

In this study, the total capital investment cannot be taken as a criterion for the solution choice since the electric power of the steam turbine varies considerably. Therefore, to 
choose the best option, a net present value or net value gain relative to the base case should be used [6].

\section{Results of the design efficiency of CCGT-BP}

The effect of the external temperature on the main annual technical and economic indicators for CCGT-BP indicates the dependences shown in Figures 2,3.

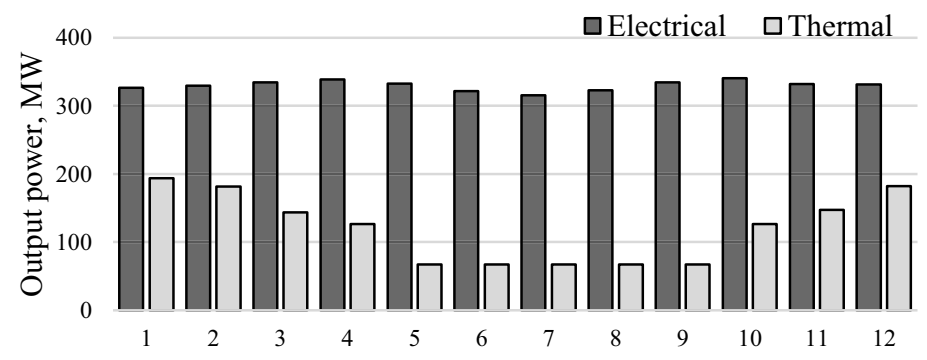

Month

Fig. 2. Change in electrical and thermal capacity of CCGT-BP throughout the year.

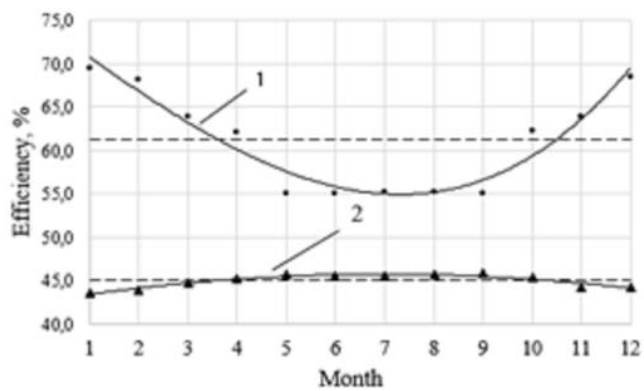

Fig. 3. Change in the total efficiency (1) and electrical efficiency of CCGT-BP (2) throughout the year. Dashed lines show average annual values of the efficiency of electrical output (45\%) and total efficiency of CCGT-BP (61.2\%)

Thermal load during the year varies significantly under change in external temperature thus changing in the total efficiency of CCGT-BP.

\subsection{Effect of the heat network chart}

Dependences of the main parameters of CCGT-BP on temperature of the heating water are presented in Fig. 4. The return water temperature is $60{ }^{\circ} \mathrm{C}$.

Reduced temperature of the heating water results in increased efficiency of the investment in the project as a result of increased electric power of the steam turbine unit and increased gain in the net present value $\triangle \mathrm{NPV}$. The values of the CCGT-BP total efficiency and that of HRSG do not depend on temperature of the heating water since useful power of HRSG does not change due to constant temperature of gases at its inlet and outlet. The results of the calculations carried out for different values of the return water temperature are shown in Fig. 5. The heating water temperature is $110^{\circ} \mathrm{C}$. 


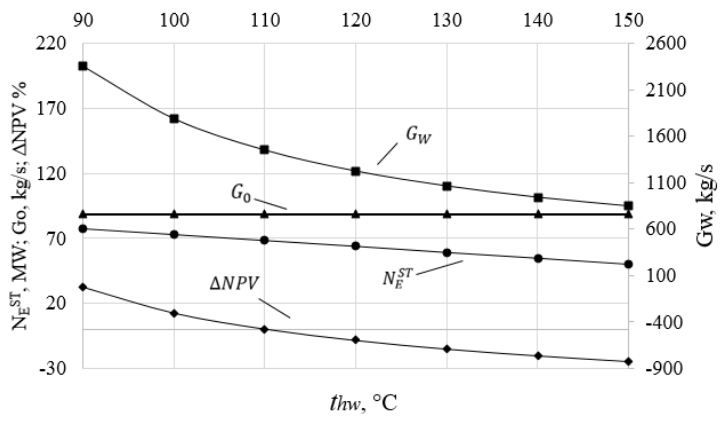

Fig. 4. Variation in CCGT-BP parameters against the temperature of the heating water.

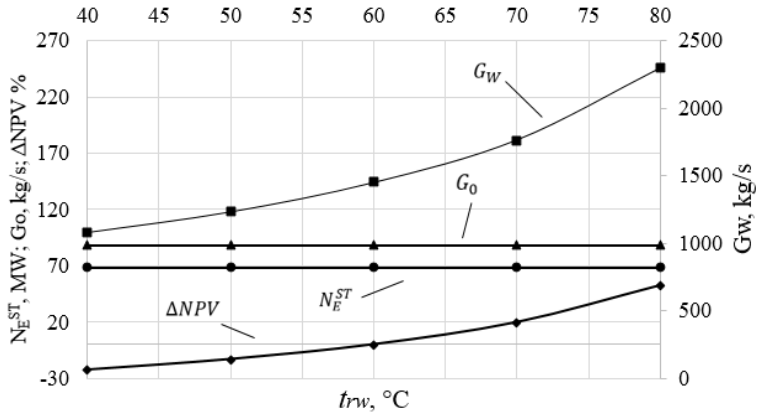

Fig. 5. Variation in CCGT-BP parameters against the temperature of the return water.

When the return water temperature grows from $40{ }^{\circ} \mathrm{C}$ to $80{ }^{\circ} \mathrm{C}$, the $\mathrm{HRSG}$ efficiency drops by $7 \%$, which reduces the amount of the delivered heat by $8.5 \%$ and reduces the total value of the CCGT-BP efficiency by $4.3 \%$. In addition, as temperature grows, the net present value $\triangle \mathrm{NPV}$ changes by $74.8 \%$.

\subsection{Effect of initial parameters of steam on CCGT-BP efficiency}

The results of calculations for the CCGT-BP steam section performed at different heating water temperature are shown in Fig. 6 . The return water temperature is $60{ }^{\circ} \mathrm{C}$; the initial parameters of steam: $5.0 \mathrm{MPa}$ and $540{ }^{\circ} \mathrm{C}$. This effect is not significant.

The growth of the initial temperature in that range (by $7.4 \%$ ) leads to a decrease in the live steam flow. At increased temperature, the electric power slightly increases regardless of the initial pressure level, and the electric power gain is 1.6-1.9 MW.

At increased initial steam pressure, the parameter of the heat transferred to each surface of HRSG, except for GWNH, decreases. As a result, the steam flow to the turbine reduces and the electric power decreases. At increased pressure, the total capital investment remains virtually unchanged: at pressure increased in the above range, it reduces by $0.73 \%-0.75 \%$. The value of $\triangle \mathrm{NPV}$ relative to the base version is negligibly negative in all the cases, and it does not virtually change. 


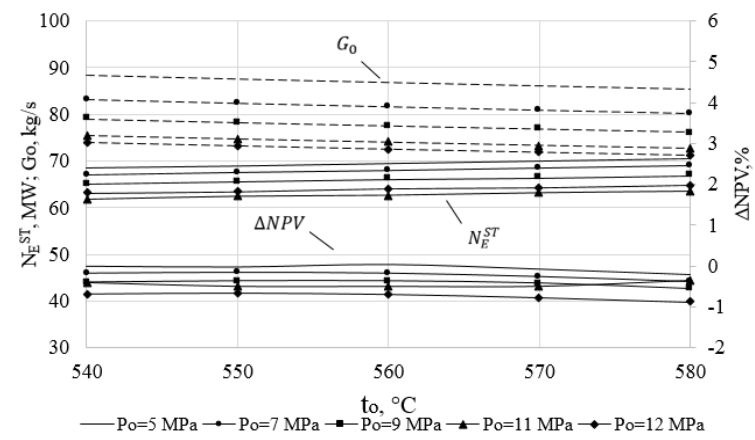

Fig. 6. Variation in CCGT-BP parameters against initial parameters of steam.

Taking into account the impact of ecological benefits of the installation can be using the software complex [7].

\section{Conclusions}

- The efficient performance of the steam section does not affect the CCGT-BP heat efficiency since bottoming cycle runs without cycle losses. In addition, simple circuit of the plant due to single-loop bottoming cycle and lack of steam reheating increases the CCGTBP reliability.

- External temperature significantly affects the CCGT-BP operation, in particular, the amount of the produced electric energy and the parameters of the steam generated by waste heat recovery boiler.

- The temperature chart of the heat network is a crucial factor for the CCGT-BP parameters since the temperature of the heating network water determines the back pressure.

- Initial steam parameters do not virtually affect the main CCGT-BP parameters. If no additional electrical power is needed, the initial vapor pressure can be decreased to $5 \mathrm{MPa}$. The study complements the results obtained in [8].

\section{References}

1. G. Olkhovsky, V. Trushechkin, Thermal power plants, 1, 2 (2013)

2. A.M. Antonova, A.V. Vorobiev, A.S. Orlov, MATEC Web Conf. 23, 01069 (2015)

3. A. Uvarov, A. Antonova, A. Vorobiev, MATEC Web Conf. 37, 01062 (2015)

4. A. Gushchin, V. Torzhkov, Turbiny i dizeli, 7, 16 (2007) [In Russian]

5. A. Trukhniy, Parogazovyye ustanovki elektrostantsiy (MEI, Moscow, 2013) [In Russian]

6. A. Devyanin, Optimizatsiya parametrov teplovyh skhem trekhkonturnyh parogazovyh ustanovok (Abstract of diss., Moscow, 2009) [In Russian]

7. A.V.Vorobiev, E.M. Dutova, A.S. Latyshev, MATEC Web Conf. 72, 01125 (2016)

8. A. Uvarov, A. Antonova, MATEC Web Conf. 91, 01013 (2016) 